\title{
1 Multi-Level Computational Exploration of Advanced Combustion 2 Engine Operating Strategies
}

\author{
3 David Vuilleumier ${ }^{\mathrm{a}} *$, Ivan Taritas ${ }^{\mathrm{b}}$, Benjamin Wolk ${ }^{\mathrm{a}}$, Darko Kozarac ${ }^{\mathrm{b}}$, Samveg \\ 4 Saxena $^{\mathrm{c}}$, Robert W. Dibble ${ }^{\mathrm{a}}$ \\ 5 a Department of Mechanical Engineering, University of California, 6141 Etcheverry Hall, Berkeley, CA \\ 6 94720-1740, USA \\ $7 \quad{ }^{\mathrm{b}}$ Faculty of Mechanical Engineering and Naval Architecture, University of Zagreb, Ivana Lucica 5, 10000 \\ 8 Zagreb, Croatia \\ $9{ }^{\mathrm{c}}$ Energy Technologies Area, Lawrence Berkeley National Laboratory, 1 Cyclotron Road, MS 90R1121, \\ 10 Berkeley, CA 94720, USA \\ $11 *$ Corresponding author. Tel: +001-916-396-6699; fax: none. \\ 12 E-mail address: david.vuilleumier@berkeley.edu
}

13 Abstract

14 Advanced combustion engine (ACE) research is typically carried out on single-cylinder research engines.

15 These engines are designed to tightly control fueling and conditions at intake valve closure (IVC) and to

16 precisely measure in-cylinder conditions and emissions. However, to be able to measure and control engine

17 operation so precisely, these research engines typically do not feature intake and exhaust tracts that

18 resemble those in production engines, specifically in regards to turbomachinery, heat exchangers, and

19 exhaust gas recirculation (EGR) systems. For this reason, these research engines are effective for

20 understanding in-cylinder combustion parameters such as heat release rate, burn duration, combustion

21 efficiency, pollutant formation, and exhaust valve opening (EVO) conditions.

22 This paper applies high fidelity simulations to determine the feasibility of achieving a chosen single

23 cylinder engine operating point on a production type homogeneous charge compression ignition (HCCI)

24 engine, using a partial fuel stratification (PFS) strategy. To accomplish this, a Converge 3 dimensional (3D)

25 - computational fluid dynamics (CFD) model of the experimental combustion chamber and intake and

26 exhaust runners was created to simulate the experimental engine. This model was used to simulate an

27 operating point achieved experimentally, as well as to determine the sensitivity of the operating point to

(C) 2016. This manuscript version is made available under the Elsevier user license http://www.elsevier.com/open-access/userlicense/1.0/ 
variations in intake pressure, intake temperature, injection timing, injected mass, and EGR fraction. The

29 results from these simulations were fed into a 1-dimensional engine simulation created in AVL Boost,

30 featuring production-type intake and exhaust systems, including turbomachinery and heat exchangers

31 necessary to create the required IVC conditions. This full engine simulation was used to assess the cycle

32 efficiency of the engine at the experimental operating condition, and to assess whether changes to this

33 operating point in intake temperature, intake pressure, direct injection timing, or fueling are beneficial to

34 the cycle efficiency and engine-out emissions. In addition, the sensitivity of promising engine operating

35 points to injection timing and injection mass are determined to evaluate the potential stability of these

36 operating points.

37 Keywords: Homogeneous Charge Compression Ignition; Partial Fuel Stratification; Gasoline Compression

38 Ignition; Low Temperature Combustion; Computational Fluid Dynamics; cycle-simulation

\section{Introduction}

40 The development of an engine operating strategy requires careful balancing of many

41 simultaneously interacting in-cylinder fundamental phenomena that determine overall

42 efficiency, emissions, stability, and noise-vibration-harshness characteristics. In the case

43 of low temperature combustion (LTC) engines, the focus of the present study, important

44 in-cylinder phenomena include chemical kinetics that determine heat release rates,

45 spatially- and temporally-varying in-cylinder charge conditions, heat transfer, fuel

46 vaporization, and emissions formation, as has been demonstrated by Saxena in [1]. These

47 fundamental phenomena can be affected by several controllable parameters, including

48 fuel type, port and direct injection strategy (including port fuel injection - PFI/direct

49 injection - DI - injection fractions, DI timing, DI duration), intake temperature and

50 pressure, equivalence ratio, EGR dilution, and engine speed. This large number of

51 controllable parameters makes it difficult to identify optimal engine operating conditions 
52 across the entire load-speed operating range. Furthermore, in-cylinder operation must be

53 managed to ensure that critical limits are not exceeded, including ringing limits, misfire

54 limits, and stability and cyclic variability limits, while maintaining acceptable overall

55 engine operating efficiency and emissions characteristics [1]. The parameter space of

56 operating variables and interacting fundamental phenomena grows even larger when

57 considering the entire engine system, which includes the aforementioned in-cylinder

58 phenomena, but also the intake and exhaust manifolds, turbocharger, intercooler, and

59 EGR system.

60 This study aims to predict performance of a gasoline fuelled homogeneous charge

61 compression ignition (HCCI) engine which employs a partial fuel stratification (PFS)

62 operating strategy. Recent studies have demonstrated PFS as a promising operating

63 strategy that can extend the operating regime of HCCI engines without exceeding the

64 aforementioned operating limits. Dec et al. [2] found that at boosted conditions, PFS

65 operating strategy is effective in increasing thermal efficiency; they increased peak

66 thermal efficiency from $47.8 \%$ for premixed fueling to $48.4 \%$ with PFS strategy. In [3]

67 the authors found that PFS enables staged combustion with reduced pressure rise rate,

68 and therefore offers a potential to increase the high load range of HCCI engine operation.

69 IMEPg increased from 537 to $597 \mathrm{kPa}$, with $\mathrm{NO}_{\mathrm{X}}$ emissions under US 2010 standards. In

70 [4], Dec et al. found PFS strategy to shift ringing/stability limits and thus allows the

71 maximum IMEPg increase from 11.7 to 13 bar. Yang et al. [5] showed that fuel

72 composition significantly affected the ability to carry out a PFS strategy, and the same

73 authors also demonstrated [6] the influence of operating conditions, namely engine speed,

74 intake temperature, and fuel composition on the efficacy of a PFS strategy. In [7], Yang 
75 et al. found that high load extension in a gasoline HCCI engine that uses PFS strategy is

76 limited by the trade-off between $\mathrm{CO}$ (retarded operation) and $\mathrm{NO}_{\mathrm{X}}$ (advanced operation)

77 emissions. In [8,9] the authors used detailed 3-D CFD analysis to study and better 78 explain the in-cylinder phenomena that occurs in HCCI engine that uses a PFS strategy.

79 They found in [8] that occurrence of single- or multi-stage combustion depends on the

80 temperature distribution which is influenced by low temperature heat release (LTHR) and

81 evaporative cooling from the liquid fuel spray. In [9] it was found that at 1 bar intake

82 pressure since the premixed portion of the charge ignites before rich regions, the

83 sequential autoignition occurs too fast and there is no reduction in the maximum pressure

84 rise rate compared to $\mathrm{HCCI}$ operation. On the other hand, at 2 bar intake pressure the

85 sequential autoignition occurs over a longer period as the premixed portion auto-ignites

86 last, which reduces maximum pressure rise rate compared to HCCI operation.

87 Given the range of engine operating variables that affect PFS performance, prior studies

88 have focused on in-cylinder operating variables without giving adequate consideration to

89 the engine system. Moreover, the majority of the experimental studies focused solely on

90 extending the high load operation limit, while the numerical ones focused on

91 understanding the fundamental aspect and impact of a PFS strategy on HCCI combustion

92 process. This paper presents a numerical study that focuses on mid-load engine operation,

$93 \sim 10.5$ bar indicated mean effective pressure (IMEP), at 1,200 RPM. The present study

94 bridges the gap between previous experimental and numerical studies by investigating an

95 HCCI engine that employs a PFS strategy using a coupling of a detailed 3D-CFD and

96 chemical kinetic combustion chamber model [10-13] with a 1D multi-cylinder engine

97 system model $[14,15]$. This approach builds off the approach which has been developed 
98 by Babajimopoulos et al. [10], Embouazza et al. [11], Wang et al. [12], and Kong et al

99 [13]. In [10], the coupling of CFD with chemical kinetics solvers is shown to be effective

100 in capturing the effects of interacting fluid dynamics and chemical kinetics, in this case

101 simulating a premixed charge compression ignition engine. In [11], tabulated chemistry is

102 coupled to CFD in order to capture the interactions between chemistry and fluid

103 dynamics. Wang et al. [12] coupled a CFD simulation to a complex 89 species gasoline

104 mechanism to simulate directly-injected gasoline HCCI combustion, while Kong et al.

105 [13] carried out a similar coupling between KIVA-3 and Chemkin, also to study directly

106 injected gasoline HCCI combustion. In [14], Ogink et al. couple the AVL Boost engine

107 simulation code, which is described in the AVL Boost Theory Manual [15], to SENKIN

108 routines for calculating chemical kinetics; this combination is used to simulate gasoline

109 HCCI combustion. The techniques which were pioneered in [11 - 14] are used in this

110 work to investigate the behavior of a PFS operating strategy.

111 3D-CFD simulations incorporating chemical kinetic combustion models are an

112 established method to study kinetically controlled combustion engines, demonstrated by

113 both Zhou et al. [16] and Li et al. [17] in simulating Reactivity Controlled Compression

114 Ignition combustion, with the former investigating biodiesel and methanol blends, and

115 the latter investigating gasoline and biodiesel blends. In the first part of the present study,

116 a detailed 3D-CFD simulation was used in performing a detailed parameter sweep to

117 identify the PFS operating parameters leading to optimal engine performance. Operating

118 parameters varied in this numerical study are intake pressure and temperature, DI timing,

119 DI mass fraction, equivalence ratio and EGR fraction. By sweeping through a narrow

120 range of controllable parameters, the sensitivity of engine performance (including 
121 efficiency, emissions, ringing intensity (RI), etc.) to many of the operating variables is

122 quantified. After identifying feasible operating points, which resulted in high indicated

123 efficiency and low exhaust gas emissions, a full model cycle-simulation, featuring a

124 detail description of a multi-cylinder engine charging and cooling elements, and entire

125 intake and exhaust flow path, was run in order to assess the overall system efficiency and

126 operating range in terms of intake temperature and engine speed.

127 2. Methods

$128 \quad$ 2.1. Combustion Model

129 3D-CFD simulations in this work were performed using CONVERGE [18], a

130 commercially available CFD code. The grid used for all CFD simulations is

131 representative of the Sandia HCCI engine [4], as shown in Figure 1. CONVERGE

132 employs a cut-cell Cartesian method for grid generation and generates a grid at each time

133 step given the position of the boundary surfaces. The previous time step solution is

134 mapped onto the new grid before solving for the next time step. This procedure naturally

135 permits the use of moving surfaces, such as the piston and intake/exhaust valves. A

136 uniform grid spacing of $2 \mathrm{~mm}$ was used, as this was the finest grid resolution that could

137 be computationally afforded. This resulted in 140,881 in-cylinder cells at bottom dead

138 center (BDC) and 13,859 in-cylinder cells at top dead center (TDC). A non-uniform,

139 adaptive grid may be required to resolve a flame surface. However, a non-uniform grid is

140 not required in this work as there is only sequential auto-ignition without flame 141 propagation. 
142 A schematic of the computational grid is shown in Figure $\mathbf{1}$ and engine specifications are

143 listed in Table 1 (values in parentheses indicate experimental values that differ from the

144 associated values used in the simulations). The geometric compression ratio (CR) of the

145 computational mesh is $13.65: 1$, which is slightly lower than the $14: 1$ used in the

146 experiment, in order to match the motored pressure trace as crevices and blow down are

147 not meshed directly.

148 The engine has two intake ports, one port with a helical geometry and one port with a

149 tangential geometry. The valve lift profiles are set using experimentally measured valve

150 lift values. The piston has a deep central bowl to prevent piston wetting at late direct-

151 injection timings. The head gasket crevice is included in the computational mesh and a

152 piston ring crevice model is used rather than direct meshing of the piston ring crevices.

153 Dimensional information about the piston rings and piston ring cutouts is used as input to

154 the piston ring crevice model.

155 Simulations are run from $360^{\circ}$ bTDC to $122^{\circ}$ aTDC. This encompasses the full intake

156 stroke to part way through the expansion, after combustion has completed and to the

157 point at which the exhaust valve opens. The intake stroke is computed to create realistic

158 thermal stratification and in-cylinder velocity profiles in the premixed intake gas.

159 Chemistry is computed only for cells with temperatures in excess of $600 \mathrm{~K}$ and is not

160 computed in the intake or exhaust ports while the respective valves are closed. This helps

161 to reduce the computational cost of the simulations, as the time for computing chemistry

162 accounts for a large fraction of the total computational effort. 


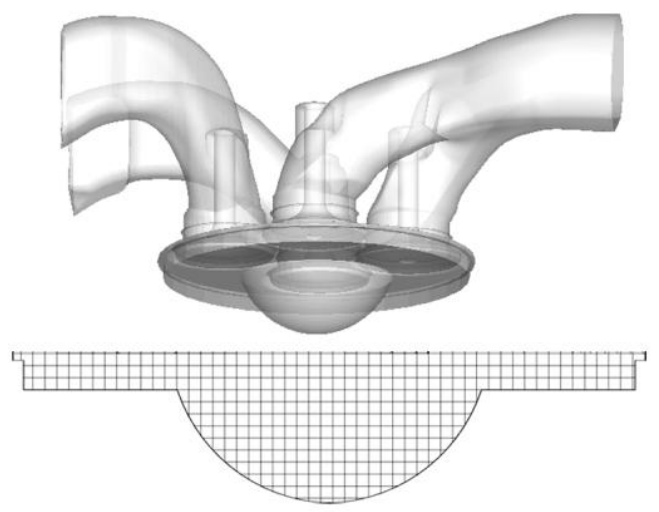

164 Figure 1: Computational surface of Sandia HCCI engine at top dead center. The in-cylinder grid is 165 shown with a grid spacing of $2 \mathbf{~ m m}$ (the full grid includes the intake and exhaust ports).

166 Table 1. Sandia HCCI engine specifications

\begin{tabular}{|l|l|}
\hline Displacement & $0.981 \mathrm{~L}$ \\
\hline Bore & $102 \mathrm{~mm}$ \\
\hline Stroke & $120 \mathrm{~mm}$ \\
\hline Connecting rod & $192 \mathrm{~mm}$ \\
\hline Geometric CR & $13.65: 1(14: 1)$ \\
\hline Number of valves & 4 \\
\hline IVO & $360^{\circ} \mathrm{BTDC}$ \\
\hline IVC & $158^{\circ} \mathrm{BTDC}$ \\
\hline EVO & $122^{\circ} \mathrm{ATDC}$ \\
\hline EVC & $368^{\circ} \mathrm{ATDC}$ \\
\hline Engine speed & $1,200 \mathrm{rpm}$ \\
\hline Intake pressure & $1.9-2.1 \mathrm{bar}$ \\
\hline Coolant temperature & $100^{\circ} \mathrm{C}$ \\
\hline
\end{tabular}

167 The gasoline used in the experiments by Dec et al. [4] and considered in this work is

168 RD387 research grade gasoline, which contains a wide range of molecular components.

169 Although the broad molecular composition has been quantified (i.e. amount of alkanes, 
170 aromatics, and olefins), specifying the exact amount of each molecule in RD387 is not

171 feasible. As a result, a surrogate containing a small number of pure components has been

172 formulated by Mehl et al. [19] to mimic major properties of RD387. The targeted

173 properties are the broad molecular composition, the $\mathrm{H} / \mathrm{C}$ ratio, stoichiometric air-fuel

174 ratio, and anti-knock index (AKI).

175 In this study, gasoline is modeled by the 4-component surrogate identified by Mehl et al.

176 [19] comprised of $57 \%$ iso-octane $\left(\mathrm{iC}_{8} \mathrm{H}_{18}\right), 16 \%$ n-heptane $\left(\mathrm{nC}_{7} \mathrm{H}_{16}\right), 23 \%$ toluene

$177\left(\mathrm{C}_{6} \mathrm{H}_{5} \mathrm{CH}_{3}\right)$, and 4\% 2-pentene $\left(\mathrm{C}_{5} \mathrm{H}_{10}-2\right)$ by liquid volume. The chemistry is modeled

178 using a 98-species reduced mechanism for the 4-component gasoline surrogate [20]

179 including $\mathrm{NO}_{\mathrm{x}}$ formation reactions and a well-mixed sub-grid chemistry model. A well-

180 mixed sub-grid chemistry model indicates that the reaction rates are evaluated at the

181 mean cell temperature (sub-grid temperature fluctuations are ignored). Despite this

182 shortcoming, well-mixed sub-grid chemistry is common among RANS engine codes.

183 Turbulence is modeled using the RNG k-epsilon turbulence model [21].

184 The fuel injector used in the experiment is an 8-hole gasoline direct injection (GDI)

185 injector that has a hole diameter of $125 \mu \mathrm{m}$, included angle of $70^{\circ}$, and injection pressure

186 of 120 bar. The injector is centrally mounted in the combustion chamber and oriented

187 vertically downward. The simulated injection uses a Lagrangian spray model and a

188 stochastic collision model (O'Rourke) with injected droplets following a Rosin-Rammler

189 distribution [22] with a Sauter mean diameter (SMD) of $125 \mu \mathrm{m}, 180 \mathrm{~m} / \mathrm{s}$ injection

190 velocity, and initial droplet temperature of $300 \mathrm{~K}$. The liquid fuel droplet breakup is

191 modeled using the Kelvin-Helmholtz Rayleigh-Taylor (KHRT) droplet breakup model

192 [23]. The KHRT breakup model evaluates the growth rates of the KH and RT instabilities 
193 to determine if a droplet breaks up due to one of these mechanisms during a 194 computational time step.

195 The boundary conditions used for solid surfaces are constant temperature. Surface

196 temperatures are set to the coolant temperature, except for the piston and head, which are

197 set to the experimentally measured head temperature. For the intake ports, the initial 198 conditions and the intake inflow compositions are set to the composition of the premixed

199 charge. For the in-cylinder region and exhaust ports, the initial composition is the 200 complete combustion products $\left(\mathrm{CO}_{2}, \mathrm{H}_{2} \mathrm{O}, \mathrm{O}_{2}, \mathrm{~N}_{2}\right)$ of the premixed gas (not including 201 additional DI fuel). The initial temperature of the intake region is the intake temperature, 202 and the initial in-cylinder and exhaust temperatures are the experimental exhaust 203 temperatures. The model used in this paper was previously validated and published in [9].

204 The agreement between experimental and simulated conditions can be seen in Figure 2,

205 Figure 3, and Figure 4. Figure 2 shows the agreement of in-cylinder pressure between

206 the simulation and the experiment for four different injection strategies at 2 bar intake

207 pressure. Figure 3 and Figure 4 show the simulated and experimental rates of heat

208 release for the same four operating points. It can be seen from the three figures that

209 generally good agreement exists between the model and the experiment. A more detailed

210 discussion of the operating points and their specific agreements with experiments can be

211 found in [9]. For this paper, the model was used nearly unaltered from that presented in

212 [9], except for the use of the 98 species kinetic mechanism rather than the 96 species

213 mechanism used in [9]. These mechanisms were both reduced from the same detailed

214 mechanism, and have nearly identical behavior, with the primary difference between 
215 them being the addition of the species $\mathrm{NO}$ and $\mathrm{NO}_{2}$ to the 98 species mechanism, for the 216 calculation of the concentrations of these pollutants.

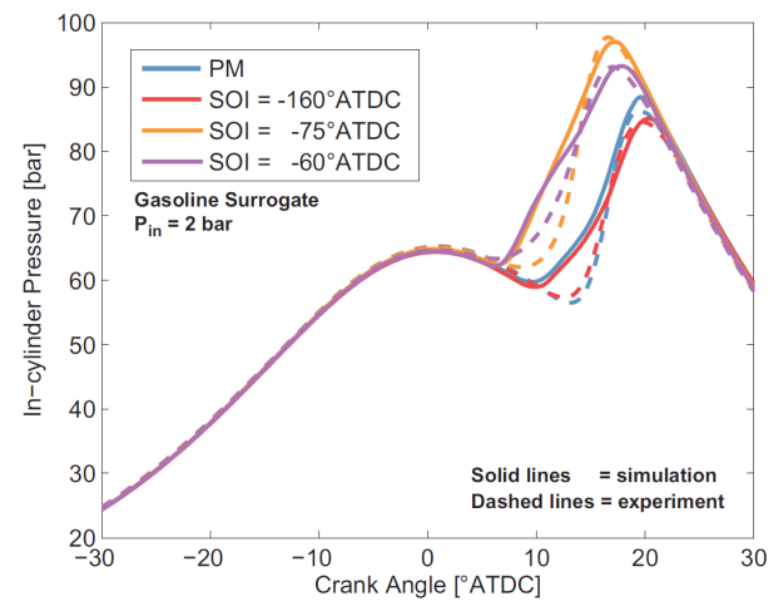

218 Figure 2: Comparison of four experimental and simulated pressure traces at 2 bar intake pressure,

219 for fully premixed (PM) and partially stratified (13\% DI) cases at two different combustion phasings

[9].

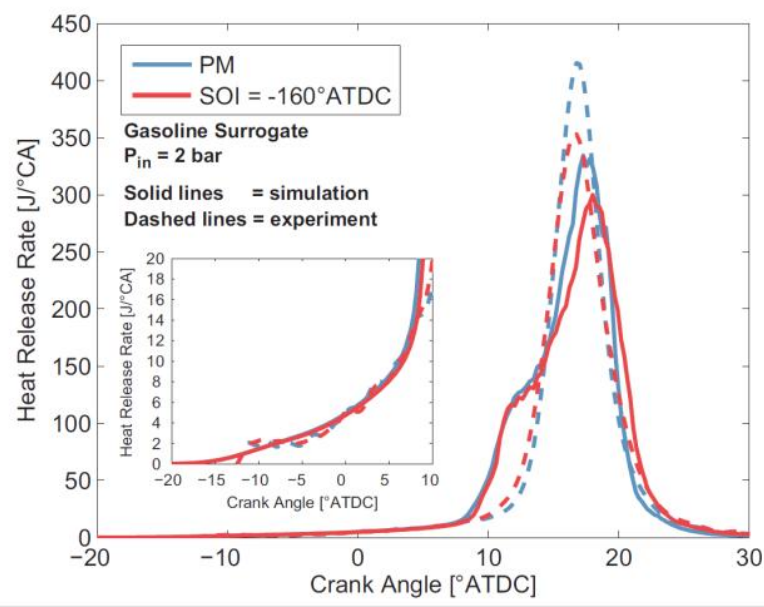

222 Figure 3: Comparison of experimental and simulated rates of heat release at 2 bar intake pressure, for fully premixed (PM) and partially stratified (13\% DI) cases [9]. 


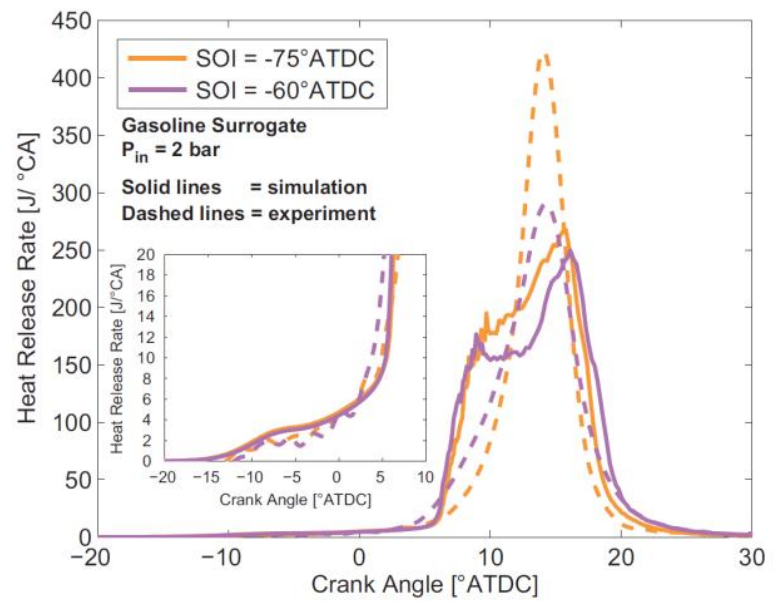

Figure 4: Comparisons between experimental and simulated rates of heat release at 2 bar intake pressure for two different injection timings for partially stratified (13\% DI) cases [9].

\subsection{Cycle-simulation}

228 The simulation of the full engine performance was performed by a cycle-simulation

229 model made in the AVL Boost. In order to obtain simulation results which accurately

230 reflect the operation of the engine, the entire engine layout featuring four cylinders and a

231 detailed description of the entire engine flow path was made, as seen in Figure 5. More

232 detailed information on this model can be found in [24].

233 In the full engine model, combustion was calculated with a table heat release model

234 which enables the calculation of many engine cycles in a reasonable time. These tables

235 were created according to the rate of heat release profiles obtained from the detailed 3D-

236 CFD simulation. The cylinder was modeled according to the cylinder geometry data,

237 which is given in Table 1. In the AVL Boost, the effect of two intake and two exhaust

238 valves is taken into account by setting the appropriate value for the scaling factor for the

239 effective intake \& exhaust flow area [15]. Heat transfer in the combustion chamber was

240 calculated with Woschni's model. More on the heat transfer calculation in the 
241 combustion chamber, as well as on the heat transfer and friction calculation in the pipe

242 elements can be found in [15].

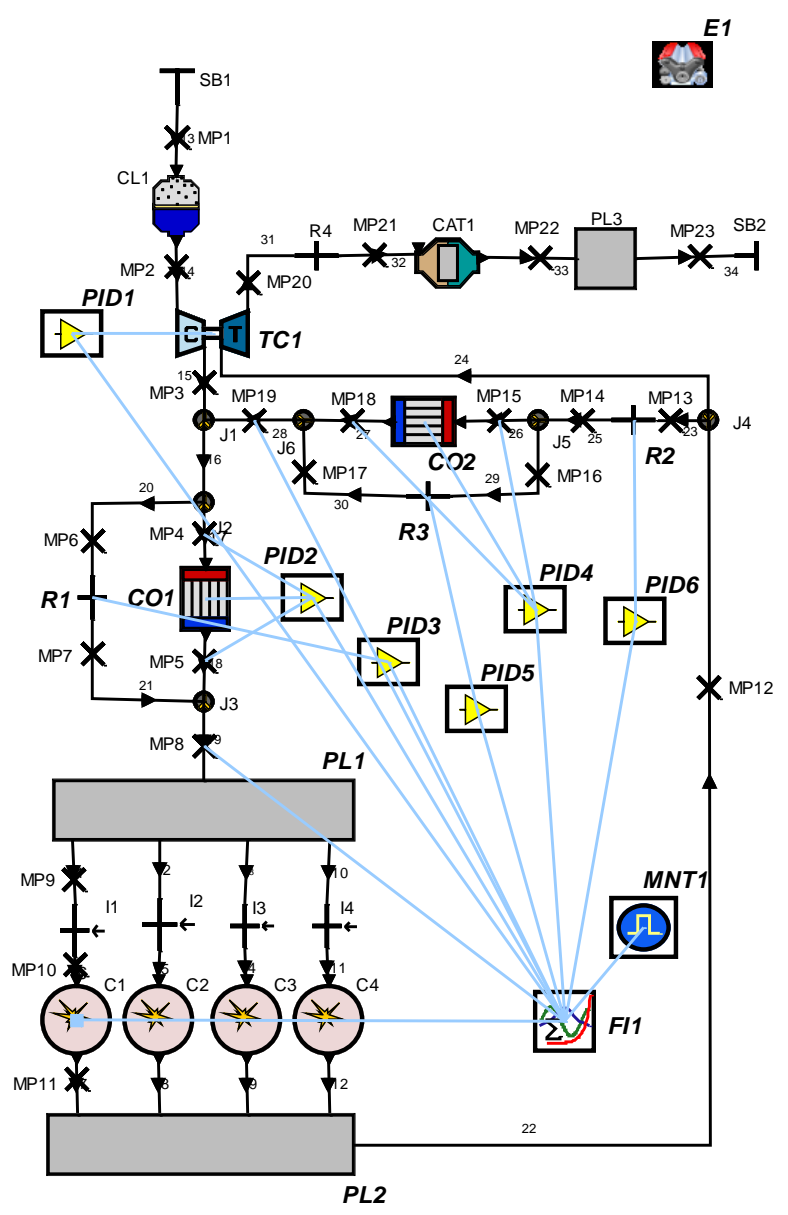

Figure 5: Full engine simulation model.

245 Variable geometry turbocharger (shown in Figure 5 as TC1) performance was calculated

246 with the full model charger calculation, which uses the turbine and compressor static

247 performance maps that were obtained from the manufacturer. As these maps present just

248 a narrow operating range of the charging device, extrapolation of the maps was

249 performed by a BOOST Turbocharger Tool [15]. Vane position was set so that the

250 appropriate pressure at the IVC is obtained. This was controlled automatically by a PID

251 controller (shown in Figure 5 as PID 1). 
252 Besides the charging element, the full engine model features an intake air cooler (shown

253 in Figure 5 as CO1) and a system to bypass it. It also features a high pressure EGR loop

254 with an EGR cooler (shown in Figure 5 as CO2) and a system to bypass it. The intake air

255 cooler is an air to air cooler, while the EGR cooler is an air to water cooler. Cooling

256 performance was calculated with the target efficiency model, which requires the input of

257 the cooler efficiency and the coolant temperature [15]. For the air to air cooler, the

258 cooling efficiency was set to $65 \%$ [25], and the coolant temperature was set to $25^{\circ} \mathrm{C}$,

259 which corresponds to the temperature of the outside air. The air to water cooler efficiency

260 was set to $90 \%$ [25], while its coolant temperature was set to $50^{\circ} \mathrm{C}$. The cooler outlet

261 temperature was controlled by the PID regulators (shown in Figure 5 as PID 2 and PID

2624 , respectively), which control the flow through the cooler bypass, thus regulating the

263 cooler outlet temperature. Cooler outlet temperature was set so that temperature at IVC

264 matches the one obtained with the detailed 3D-CFD simulation. If no cooling is needed,

265 cooler flow coefficients are set to zero, while the bypass restrictors are kept fully open,

266 which means that the entire charge flows through the bypass. The external EGR loop is

267 also equipped with a controllable valve (shown in Figure 5 as R1) that enables the

268 control of the amount of combustion products that are recirculated back to the intake

269 manifold. The amount of EGR in the intake was controlled by a PID controller (shown in

270 Figure 5 as PID 6), and was set so that it matches the amount that was simulated with a

271 detailed 3D-CFD model.

272 As classical species transport was used, a 4-component surrogate fuel (details can be

273 found in the previous section) was created with a BOOST Gas Properties Tool [15]. The

274 same injection strategy as in the 3D-CFD model was used, where a portion of the fuel 
275 was injected into the intake port, while the remaining fuel was injected into the cylinder

276 during the compression stroke. Fuel evaporation was modeled with a standard

277 evaporation model available in AVL Boost [15].

278 The first set of the full engine simulations was performed to analyze the entire engine

279 performance for the three most interesting points obtained with the 3D-CFD simulation.

280 Operating parameters of these points are given in the next section.

281 The second set of the full engine simulations was performed to analyze the operability

282 limit in terms of the simulation-boundary intake temperature (SB1 in Figure 5), for the

283 most interesting points simulated with a detailed 3D-CFD model. These simulations were

284 performed in order to determine the lowest and the highest intake temperature that would

285 still be able to achieve the desired intake valve closure (IVC) temperature. The lowest

286 intake temperature case presumes operation with uncooled EGR and intake air charge,

287 while the highest intake temperature presumes the operation with the maximum cooling

288 capacity. Hence, six simulations were run in this set, and the details regarding the

289 operating parameters of these points are given in the next section.

290 Finally, the third set of the full-engine simulations was performed to analyze the engine's

291 operability range in terms of engine speed (turbocharger matching). Eight simulations

292 were run in this set, and details regarding the operating parameters of these points are

293 given in the next section. Since these operation points were not simulated with a 3D-CFD

294 model, due to lack of validation data, reference rates of heat release were not available.

295 Hence, the combustion was calculated with a Vibe model, whose parameters were tuned

296 so that the ROHR profile has a bell like shape; start of combustion was set to $4.9 \operatorname{degCA}$ 
297 ATDC and combustion duration was set to 6.3 degCA. These values were chosen 298 according to the values obtained in the base operating point at 1,200 rpm. Moreover, as

299 there is no data on the fuel mass for these operating points, fueling was set so that the

300 overall charge to fuel ratio ( $\mathrm{C} / \mathrm{F}$ ratio) was approximately 34.5 . This $\mathrm{C} / \mathrm{F}$ ratio was chosen

301 so that it equals the one that was simulated in the base operating point at the engine speed

302 of 1,200 rpm. Since there is no data on the EGR fractions for these operating points,

303 simulated EGR fractions were set to $28.6 \%$ for the first sweep, and $20 \%$ for the second

304 sweep. Also, as there was no data on the IVC pressure and temperature for these

305 operating points, the desired values were set according to the base operating point at

$3061,200 \mathrm{rpm}(2.01 \mathrm{bar}$ and $384 \mathrm{~K})$.

$307 \quad 3$. Results and Discussion

$308 \quad 3.1$ Combustion Model Results

309 Table 2. Key engine operation variables.

\begin{tabular}{|l|l|l|}
\hline Variable & Unit & Range \\
\hline Intake Pressure & Bar & $1.9-2.1$ \\
\hline Intake Temperature & Kelvin & $336-377$ \\
\hline Direct Injection Timing & CAD bTDC & $25-130$ \\
\hline Direct Injection Fraction & - & $0.08-0.19$ \\
\hline Charge-Mass Equivalence Ratio & - & $0.4-0.45$ \\
\hline Exhaust Gas Recirculation Fraction & - & $0.2-0.4$ \\
\hline
\end{tabular}


311 Table 3. Detailed intake parameters and results for five engine operating conditions. Note that points 3123 and $\mathbf{4}$ are only used for Ringing Analysis.

\begin{tabular}{|c|c|c|c|c|c|c|}
\hline Variable & Unit & Base Case & $\mathbf{P 1}$ & $\mathbf{P 2}$ & $\mathbf{P 3}$ & $\mathbf{P 4}$ \\
\hline Intake Temperature & $\mathrm{K}$ & 359 & 349 & 362 & 372 & 367 \\
\hline Intake Pressure & Bar & 2.00 & 1.98 & 1.90 & 2.10 & 1.90 \\
\hline Injection Timing & dADTC & -75 & -100 & -100 & -100 & -75 \\
\hline EGR & $\%$ & 29 & 14 & 22 & 29 & 22 \\
\hline Engine Speed & RPM & 1,200 & 1,200 & 1,200 & 1,200 & 1,200 \\
\hline IMEP & bar & 10.6 & 10.63 & 10.6 & 10.44 & 9.87 \\
\hline Direct Injected Fraction & - & 0.13 & 0.08 & 0.20 & 0.08 & 0.14 \\
\hline Equivalence Ratio & - & 0.43 & 0.41 & 0.44 & 0.4 & 0.41 \\
\hline UHC & $\mathrm{g} / \mathrm{kW}-\mathrm{hr}$ & 0.3 & 0.27 & 0.31 & 0.33 & 0.34 \\
\hline $\mathrm{O} 2$ & $\mathrm{~g} / \mathrm{kW}-\mathrm{hr}$ & 456 & 730 & 510 & 518 & 586 \\
\hline $\mathrm{CO}$ & $\mathrm{g} / \mathrm{kW}-\mathrm{hr}$ & 1.68 & 1.65 & 1.67 & 1.82 & 1.8 \\
\hline $\mathrm{CO} 2$ & $\mathrm{~g} / \mathrm{kW}-\mathrm{hr}$ & 968 & 760 & 860 & 982 & 874 \\
\hline NOx & $\mathrm{g} / \mathrm{kW}-\mathrm{hr}$ & 0.98 & 0.14 & 2.72 & 0.14 & 1.82 \\
\hline Efficiency & - & 43.0 & 43.4 & 43.2 & 43.3 & 43.5 \\
\hline CA10 & Degrees & 6.8 & 9 & 7.2 & 6.8 & 5.8 \\
\hline CA50 & Degrees & 11.1 & 12.7 & 10.2 & 9.6 & 9.5 \\
\hline CA90 & Degrees & 13.6 & 15 & 12.8 & 11.3 & 11.6 \\
\hline Combustion Duration & Degrees & 8.3 & 9.2 & 6.9 & 6.3 & 7.2 \\
\hline Ringing Intensity & $\mathrm{MW} / \mathrm{m}^{\wedge} 2$ & 3.9 & 4.6 & 3.7 & 11.6 & 6.3 \\
\hline $\begin{array}{l}\text { Maximum Cylinder } \\
\text { Pressure }\end{array}$ & Bar & 112 & 109 & 113 & 123 & 112 \\
\hline $\begin{array}{l}\text { Maximum Cylinder } \\
\text { Temperature }\end{array}$ & $\mathrm{K}$ & 2,538 & 2,190 & 2,572 & 2,230 & 2,583 \\
\hline $\begin{array}{l}\text { Maximum Average } \\
\text { Cylinder Temperature }\end{array}$ & $\mathrm{K}$ & 1,928 & 1,901 & 1,983 & 1,921 & 1,943 \\
\hline
\end{tabular}


313 The combustion modeling portion of this study focused on conducting a parametric

314 variable sweep around an experimentally-validated simulated engine operating point.

315 Important engine operating parameters, listed in Table 2, were varied in an effort to

316 assess the performance of the original operating point against similar operating points

317 that would provide similar load levels. These operating points characterize mid-load

318 operation (IMEP of approximately 10.5 bar) at low engine speed (1,200 RPM). In total,

319212 simulations were run, using approximately 150,000 CPU hours.

320 A primary focus of this study is the closed-cycle efficiency, as this will have a significant

321 influence on efficiency and exhaust gas emissions. In Figure 6 and Figure 7, cycle

322 efficiency is plotted against combustion phasing and combustion duration, respectively.

323 In these figures, three possible operating points are indicated by special markers, while

324 all other operating points are indicated by round black markers. The specific conditions

325 relating to these three operating points, as well as two others that will be discussed later,

326 can be found in Table 3. It can be seen from Figure 6 and Figure 7 that the peak

327 efficiencies indicated by the simulations range between $43-44 \%$. Also, it can be seen in

328 Figure 6 that a relatively wide range of combustion phasings yield high indicated

329 efficiencies, with phasings ranging from the earliest tested (4 CAD aTDC) to

330 approximately $14 \mathrm{CAD}$ aTDC yielding efficiencies above $42 \%$. This trend of efficiencies

331 is driven by the effects of heat transfer, thermodynamics, and combustion efficiency. In

332 this case, early combustion phasings yielded high combustion efficiency and high

333 thermodynamic efficiency, while not incurring enough of a heat transfer penalty to

334 reduce efficiency. As will be discussed later, earlier combustion phasing was not tested

335 due to limits placed on Ringing Intensity. At later combustion phasings, there is a 
336 thermodynamic penalty on efficiency, as a portion of the expansion stroke is left

337 effectively unused, and this accounts for the majority of the drop in overall efficiency at

338 later combustion phasings. At extremely late combustion phasings, a combustion

339 efficiency penalty may occur as well, though as can be seen in Figure 8 and Figure 9,

340 unburned hydrocarbon (UHC) and carbon monoxide (CO) emissions are similar under

341 most conditions, as cases with partial or full misfires have been omitted from these

342 results as they are unfeasible for engine operation. In the PFS combustion system, and at

343 the mid-load conditions that are studied here, the UHC and CO emissions are primarily

344 from charge that is present in the crevice and near-wall regions during combustion. This

345 can be seen most clearly in Figure 8; as combustion phasing is delayed, a lower fraction

346 of the charge is present in the crevice and near-wall regions (due to combustion occurring

347 later in the expansion stroke, resulting in a higher combustion chamber volume), resulting

348 in slightly decreased carbon monoxide emissions.

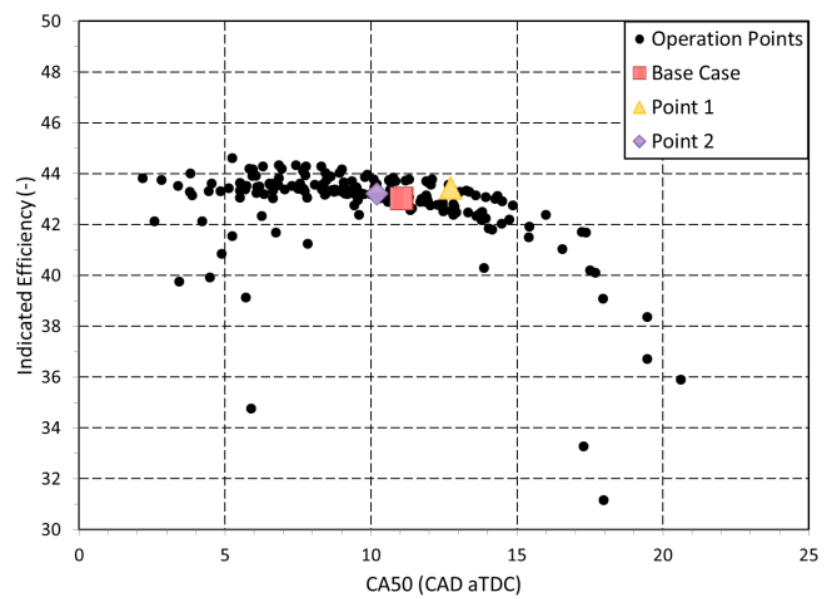

$350 \quad$ Figure 6: Indicated efficiency plotted against combustion phasing for all operating conditions evaluated using the combustion model. 


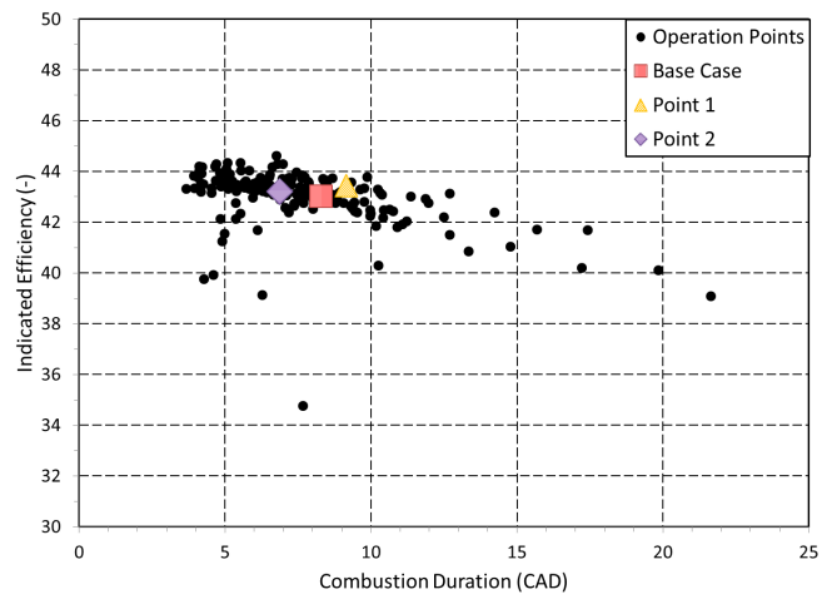

353 Figure 7: Indicated efficiency plotted against combustion duration for all tested operating conditions.

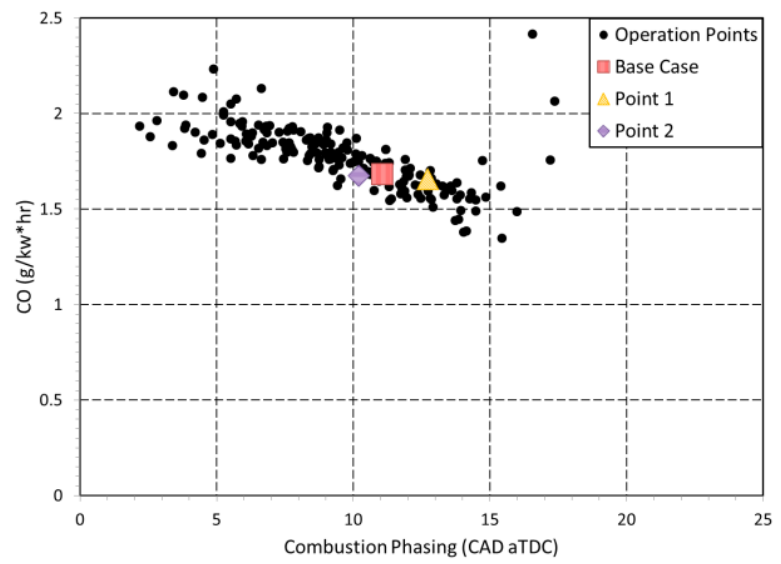

Figure 8: Carbon Monoxide (CO) emissions as a function of combustion phasing.

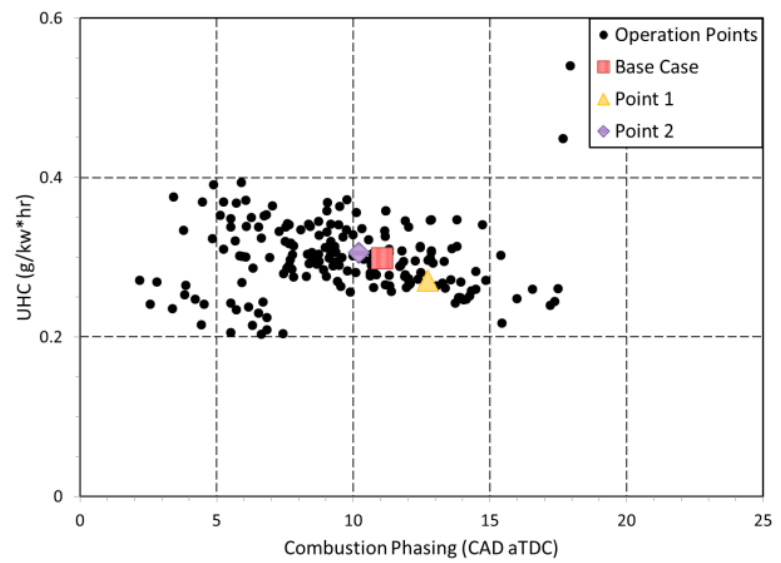

Figure 9: Unburned Hydrocarbons (UHC) emissions as a function of combustion phasing. 
358 The sweep of engine operating conditions identified two potential engine operating points

359 in addition to the base case from which the permutations were based on. Point 1 improves

360 upon the base case in the main metrics used for this study: indicated efficiency and $\mathrm{NO}_{\mathrm{x}}$

361 emissions, while maintaining acceptable RI. Thus, Point 1 would be a preferred operating

362 point to the Base Case under most circumstances. Point 2, on the other hand, reduced RI

363 and increased control over combustion phasing at the expense of $\mathrm{NO}_{\mathrm{x}}$ production and

364 indicated efficiency. Therefore, this operation point may be favored in an environment in

365 which Point 1 cannot be achieved due to the lower required intake temperature or in

366 which RI must be reduced. From Figure 6 and Figure 7 it can be seen that points exist

367 with greater efficiencies than the three points that were chosen. However, it will be seen

368 in figures presented later in this paper that these points were unsuitable either from a

369 standpoint of $\mathrm{RI}$, or $\mathrm{NO}_{\mathrm{x}}$ emissions, or both.

$370 \mathrm{NO}_{\mathrm{x}}$ emissions are a particular problem for lean burn engines that cannot make use of a

371 3-way catalyst. As seen in Figure 10, $\mathrm{NO}_{\mathrm{x}}$ emissions were highly dependent on

372 combustion phasing, and fuel inhomogeneity (in this case a function of DI fractions and

373 injection timings). This trend is easily explained by the thermal dependence of $\mathrm{NO}_{\mathrm{x}}$ via

374 the Zeldovich mechanism [26]. As seen in Figure 10, the $\mathrm{NO}_{\mathrm{x}}$ emissions correspond

375 closely with the peak cell temperature encountered by each operating condition. The peak

376 temperature, in turn, was influenced by both the mixture preparation and the combustion

377 phasing. In general, the higher DI fractions had significantly higher $\mathrm{NO}_{\mathrm{x}}$ than the lower

378 DI fractions for a given combustion phasing. This is caused by a larger amount of fuel

379 mass close to stoichiometric conditions at the point of auto-ignition, which results in

380 higher localized post-combustion temperatures. Therefore, to keep $\mathrm{NO}_{\mathrm{x}}$ emissions low 
381 while using a more aggressive DI strategy (possibly as a control strategy), a later 382 combustion phasing is required. However, combustion phasings late enough to ensure 383 low $\mathrm{NO}_{\mathrm{x}}$ also begin to reduce the indicated efficiency of the high pressure cycle, and 384 push the operating point closer to the misfire limit. Therefore, reducing the DI fraction 385 seems more favorable for this mid-load condition.

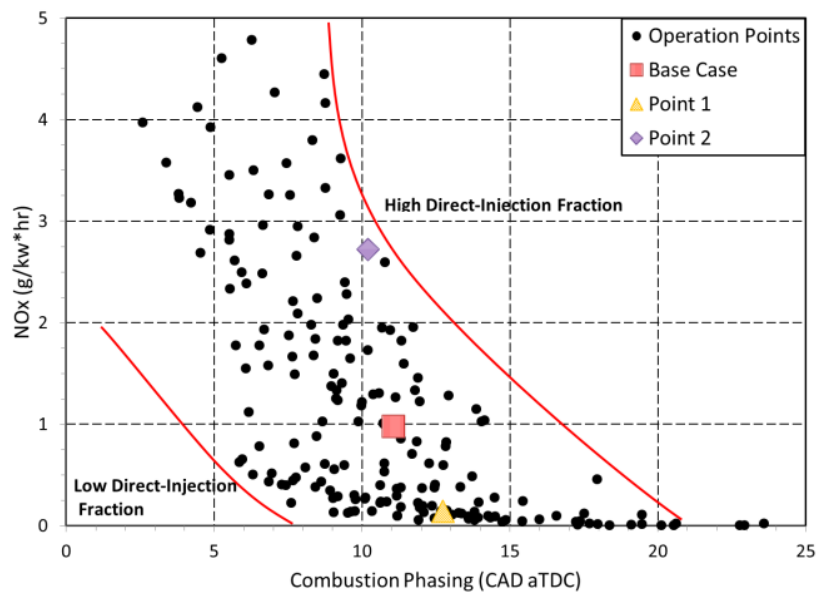

Figure 10: Plot of NOx emissions against combustion phasing for all operating points.

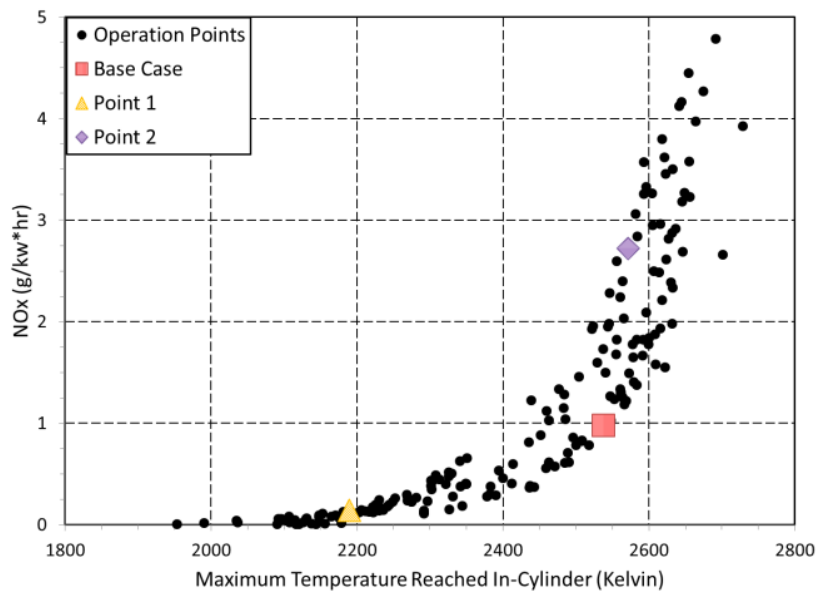

389 Figure 11: Plot of NOx emissions against the maximum temperature reached in the cylinder during the complete engine cycle.

391 A critical index for safe engine operation of advanced combustion engines (ACE's) is the

392 RI. This parameter quantifies the degree e of engine- 
393 damaging pressure oscillations that are occurring in the cylinder due to combustion.

394 Figure 12 shows the level of ringing that occurs in the simulated engine operating points.

395 In this figure a threshold is marked at $5 \mathrm{MW} / \mathrm{m}^{2}$, which has become the accepted

396 maximum level of RI for production engines [27]. From Figure 12 it can be seen that RI

397 is closely related to combustion phasing, with later combustion phasings reducing the RI.

398 Late combustion phasing helps reduce ringing because as

399 phasing is delayed, the piston is more rapidly increasing the volume of the combustion

400 chamber as combustion occurs, which in turn reduces the pressure rise rate and maximum

401 temperature in the cylinder. Figure 12 also shows that for a given combustion phasing,

402 RI can vary on the order of $50 \%$, indicating that factors other than combustion phasing 403 can have a large influence on ringing.

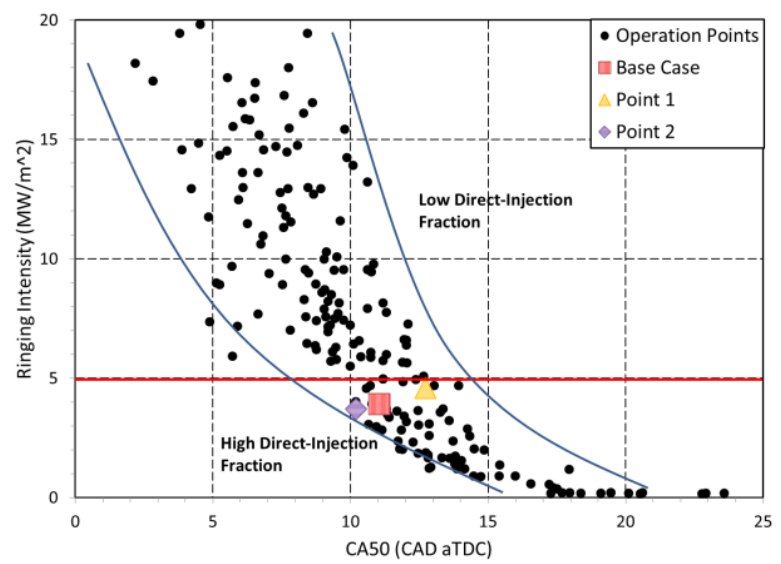

Figure 12: Plot of RI against combustion phasing for all operating points. An upper limit of ringing for this engine is shown by the red line.

407 Figure 13 plots the rate of heat release for four cases: the two cases of interest, and two

408 additional cases, Point 3 and Point 4. Point 3 and Point 4 have nearly identical CA50's, of

$409 \sim 9 \mathrm{CAD}$ aTDC, however their RI's are 11.6 and $6.3 \mathrm{MW} / \mathrm{m}^{\wedge} 2$, respectively. The cause

410 of these radically different RI's can be found in their ROHR profiles, as seen in Figure

411 13. These figures show the different manners in which Points $3 \& 4$ burn. Point 4 has a 
412 significantly lower peak ROHR; this peak ROHR is caused by the ignition of the nearly-

413 homogeneous bulk-charge. Point 4 has a smaller bulk charge mass than Point 3 . This is

414 due to the greater fuel stratification found in Point 4, which is caused by a later direct

415 injection which contains more fuel than the direct injection strategy employed in Point 3.

416 As seen in Figure 14, the higher peak ROHR results in a higher pressure rise rate, which

417 in turn raises the RI.

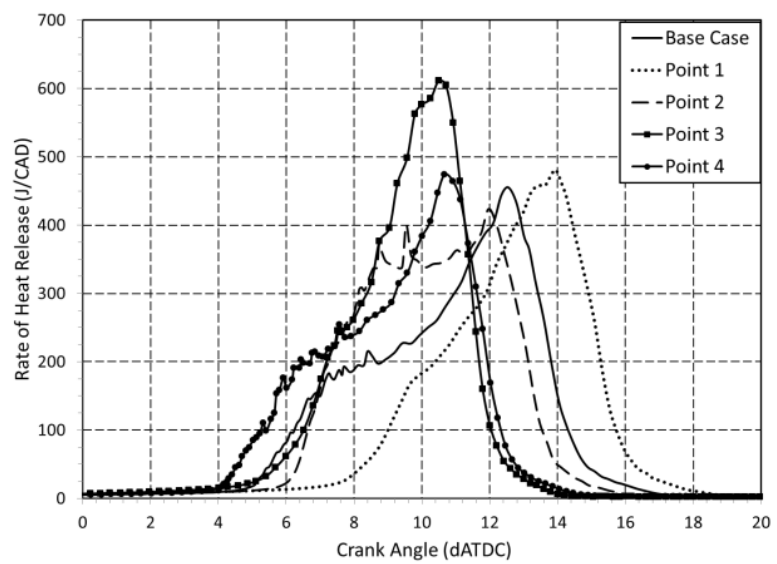

Figure 13: Rate of heat release profiles for five operating points.

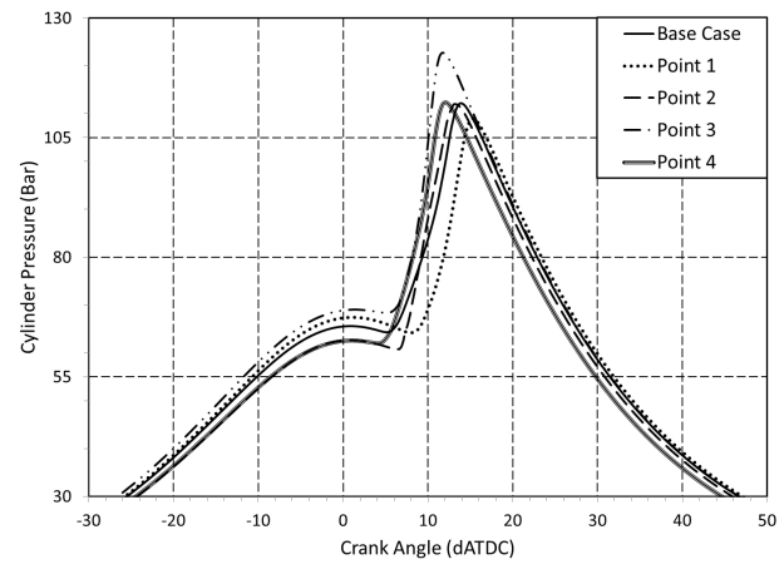

Figure 14: In-cylinder pressure traces for five operating points of interest. 
422 Finally, direct-injection timing and mass sweeps were conducted to assess the ability to

423 use the directly-injected fuel to help control combustion phasing during engine operation.

$424 \quad$ Figure 15 and Figure 16 show the results of these sweeps.

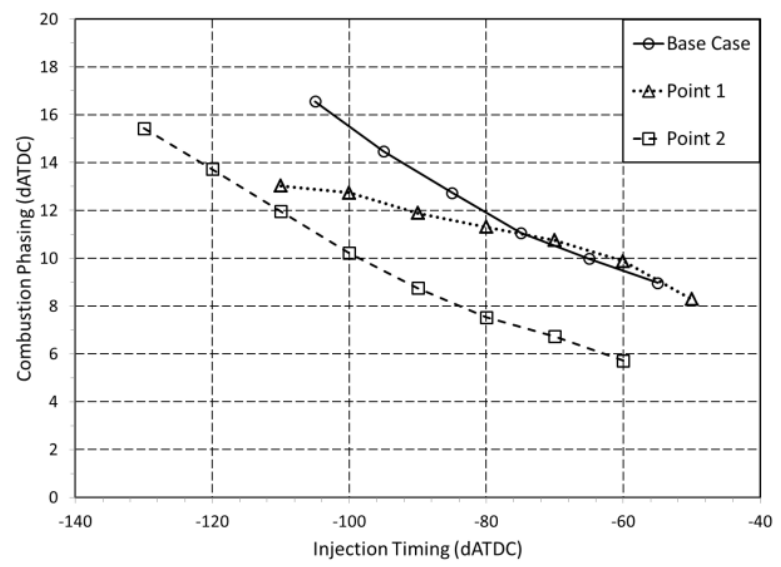

Figure 15: Combustion phasing (CA50) plotted against direct injection timing. In this sweep, the mass of both the aspirated and directly injected fuel is held constant for each case.

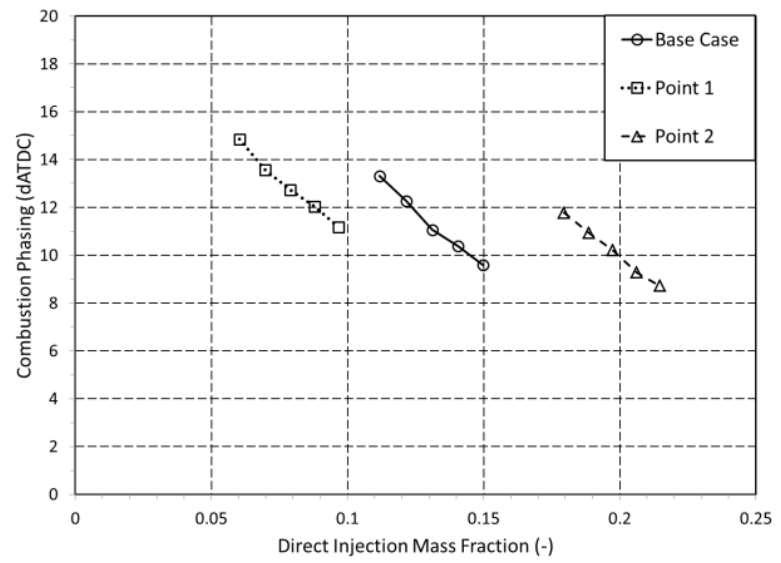

Figure 16: Combustion phasing (CA50) plotted against direct injection mass fraction.

430 In this sweep, the mass of the aspirated fuel is held constant while the mass of the directly

431 injected fuel varies. It can be seen in Figure 15, that the Base Case and Point 2 both

432 demonstrate significant control over combustion phasing with the injection timing sweep.

433 However, Point 1 shows significantly reduced control over combustion phasing relative 434 to the other points, as indicated by the difference in slope of the Point 1 dataset compared 
435 to Points 2 and 3. This is likely due to the lower direct-injection mass fraction in Point 1,

436 resulting in a smaller perturbation of the in-cylinder conditions at TDC, reducing the

437 effect on combustion phasing. This effect is obviously nonlinear, as the Base Case and

438 Point 2 show similar control over combustion phasing even though they have different

439 direct-injection mass fractions. However, it can be seen in Figure 16 that when the

440 direct-injection mass fraction is altered, all three points have similar changes in CA50. It

441 should be noted, however, that in the range tested, the timing sweep has a larger effect on

442 CA50 while not altering the fuel energy level, though in the case of Point 1 , the timing

443 sweep could not alter the combustion phasing over a wide range.

\section{$444 \quad 3.2$. Cycle Simulation Results - Complete Engine Performance}

445 Complete engine performance was estimated for only three operating points (as seen in

446 Table 4).

447 Table 4. Simulated key operating points.

\begin{tabular}{|l|l|l|l|l|l|}
\hline Operating Point & $\begin{array}{l}\text { Engine Speed } \\
(\mathbf{r p m})\end{array}$ & $\begin{array}{l}\text { Pressure at IVC } \\
(\mathbf{b a r})\end{array}$ & Temperature at IVC (K) & $\begin{array}{l}\text { EGR } \\
(\%)\end{array}$ \\
\hline Base & 1,200 & 2.01 & 384 & 28.6 \\
\hline Point 1 & 1,200 & 1.99 & 371 & 20 \\
\hline Point 2 & 1,200 & 1.93 & 382 & 20 \\
\hline
\end{tabular}

448 In the full engine performance calculation, combustion was calculated with a table heat

449 release model, with tables that were created according to the rate of heat release profiles

450 obtained from the detailed 3D-CFD simulation. Figure 17 shows that the there is a good

451 fit between the pressure traces obtained in the 3D-CFD and Boost simulation. 
452 The variable geometry turbocharger was chosen so that the compressor operates in the

453 optimum area in the engine operating points of interest, as seen in Figure 18. The engine

454 performance results obtained with the full engine simulation are presented in Table $\mathbf{5}$ and

\section{Table 6.}
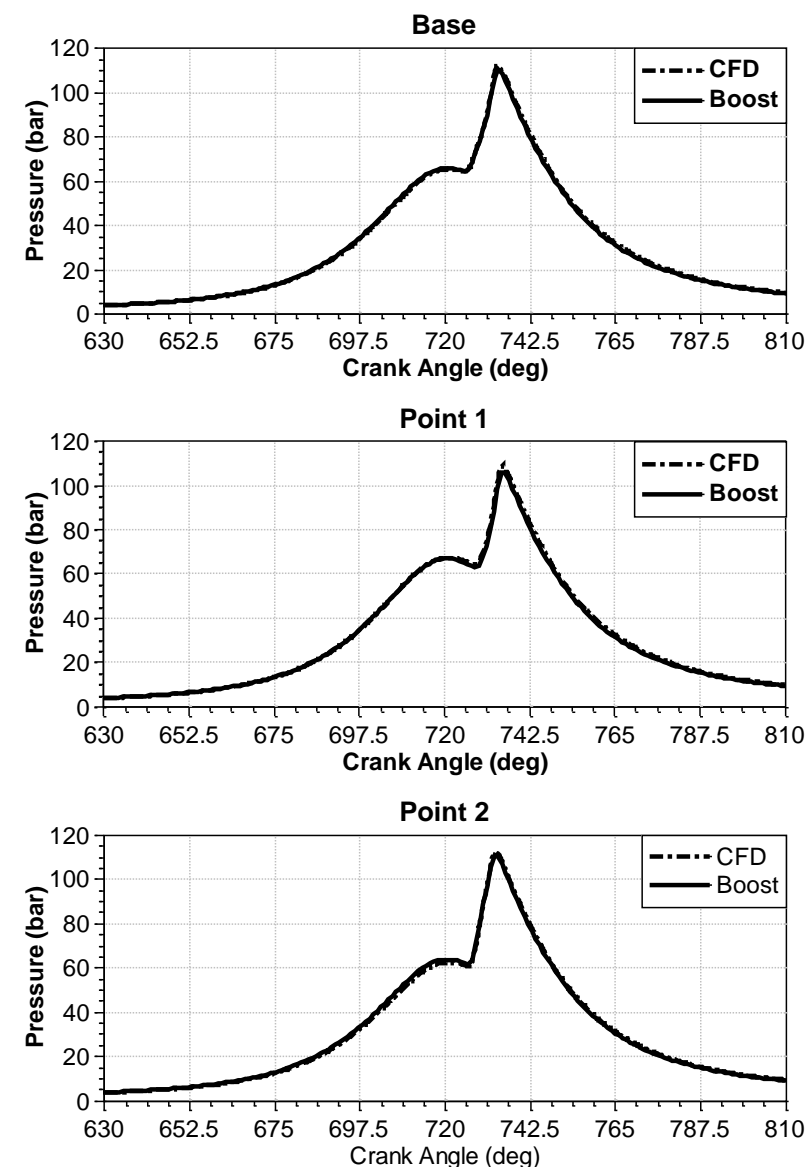

458 From the simulation results, it can be seen that similar overall performance was obtained

459 in all three operating points of interest. The highest output work was obtained in the base

460 operating point, which comes as a combined result of the higher fueling rate and the

461 overall system performance. Lower brake efficiency was obtained in operating Point 1,

462 compared to the Base and Point 2 operating points. This is a result of higher pumping 
463 losses, which is evident from a higher exhaust backpressure, which comes as a 464 consequence of the lower turbine inlet temperature (Table 6).

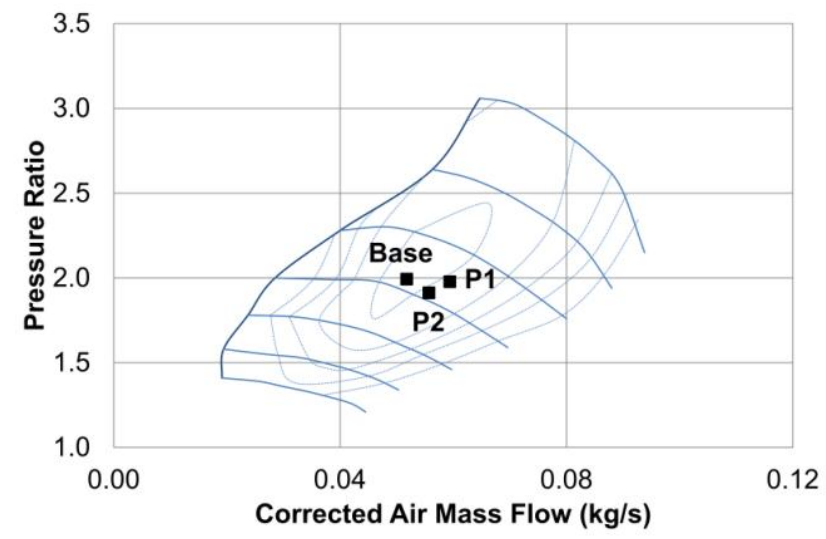

466 Figure 18. Compressor performance map with the referenced operating points plotted in it.

467 Table 5. The engine performance obtained with the full engine simulation $\left(\eta_{E}-\right.$ the engine brake 468 efficiency; $\mathbf{p}_{\mathrm{INT}}-$ intake pressure; $\mathbf{p}_{\mathrm{EXH}}-$ exhaust pressure)

\begin{tabular}{|l|l|l|l|l|}
\hline $\begin{array}{l}\text { Operating } \\
\text { Point }\end{array}$ & $\begin{array}{l}\text { BMEP } \\
(\mathbf{b a r})\end{array}$ & $\begin{array}{l}\boldsymbol{\eta}_{\mathrm{E}} \\
(\boldsymbol{\%})\end{array}$ & $\begin{array}{l}\mathbf{p}_{\text {INT }} \\
(\mathbf{b a r})\end{array}$ & $\begin{array}{l}\mathbf{p}_{\text {EXH }} \\
(\mathbf{b a r})\end{array}$ \\
\hline Base & 9.57 & 38.96 & 1.94 & 2.45 \\
\hline Point 1 & 9.44 & 38.8 & 1.97 & 2.5 \\
\hline Point 2 & 9.52 & 38.96 & 1.91 & 2.32 \\
\hline
\end{tabular}

469 Table 6. The system performance obtained with the full engine simulation $\left(\mathbf{P}_{\mathrm{EGR}}\right.$, CooLER - the 470 calculated heat flux at EGR cooler; $\mathbf{P}_{\text {INTERCOOLER }}$ - the calculated heat flux at intercooler

\begin{tabular}{|c|c|c|c|c|c|}
\hline $\begin{array}{l}\text { Operating } \\
\text { Point }\end{array}$ & $\begin{array}{c}\text { P }_{\text {EGR,COOLER }} \\
\text { (W) }\end{array}$ & $\begin{array}{c}\text { PINTERCOOLER } \\
\text { (W) }\end{array}$ & $\begin{array}{l}\mathbf{T}_{\text {EXH }} \\
(\mathbf{K})\end{array}$ & $\begin{array}{c}\eta_{\text {СOMP }} \\
(\%)\end{array}$ & $\begin{array}{l}\boldsymbol{\eta}_{\mathrm{TC}} \\
(\%)\end{array}$ \\
\hline Base & 7,486 & 0 & 789 & 73.7 & 39 \\
\hline Point 1 & 6,447 & 934 & 777 & 72.9 & 37.8 \\
\hline Point 2 & 4,069 & 0 & 799 & 73 & 37.5 \\
\hline
\end{tabular}


471 The overall turbocharger efficiency was quite high in all three operating points. The base

472 operating point had the highest turbocharger efficiency, which is a result of the position

473 of the turbine stator blade that the turbine was operated at. Point 1 and Point 2 were

474 operated with more opened turbine stator blades which is a result of the lower EGR

475 requirement and hence higher exhausts mass flow at the turbine. Slightly lower

476 turbocharger efficiency in these operating points is a result of the lower turbine efficiency

477 at this stator blade position. Although Point 2 has lower turbocharger efficiency

478 compared to the Base point, this point has the lowest pumping losses, which comes as a

479 result of the highest exhaust (turbine inlet) temperature, which enables the operation with

480 lower exhaust (turbine inlet) pressure.

481 The highest cooling requirement was in the base operating point, as a result of the highest

482 amount of EGR that had to be cooled. It can be seen that intercooler only had to be 483 applied in the Point 1 operating point. This is a result of low EGR rate (20\%) in the 484 combination with a low IVC temperature requirement Table 6.

\subsection{Cycle Simulation Results - Engine Operability Range}

486 The low and high intake temperature range was analyzed with a table heat release model

487 at the engine speed of $1,200 \mathrm{rpm}$. The operating points that were analyzed are specified in $488 \quad$ Table 7.

489 The engine could be operated in all three operating points at $-70^{\circ} \mathrm{C}$ and $70^{\circ} \mathrm{C}$. To obtain 490 the desired IVC temperature at $-70^{\circ} \mathrm{C}$, the EGR cooler had to be engaged, which means 491 that even lower intake temperature could be obtained. However, as such low temperatures 492 are not expected, $-70^{\circ} \mathrm{C}$ was set as a low temperature limit. Also, at $70^{\circ} \mathrm{C}$ the desired IVC 
493 temperature was obtained without the intercooler operating at full capacity, which means

494 that even higher intake temperature could be obtained. However, as such high

495 temperatures are not expected, $70^{\circ} \mathrm{C}$ was set as a high temperature limit.

496 Table 7. Simulated operating points for high- and low-temperature limits.

\begin{tabular}{|c|c|c|c|c|}
\hline $\begin{array}{c}\text { Operating } \\
\text { Point }\end{array}$ & $\begin{array}{c}\text { Engine Speed } \\
\text { (rpm) }\end{array}$ & $\begin{array}{c}\text { Pressure at IVC } \\
\text { (bar) }\end{array}$ & Temperature at IVC (K) & $\operatorname{EGR}(\%)$ \\
\hline Base - Low & 1,200 & 2.01 & 384 & 28.6 \\
\hline Base - High & 1,200 & 2.01 & 384 & 28.6 \\
\hline $\begin{array}{c}\text { Point } 1- \\
\text { Low }\end{array}$ & 1,200 & 1.99 & 371 & 20 \\
\hline $\begin{array}{c}\text { Point 1- } \\
\text { High }\end{array}$ & 1,200 & 1.99 & 371 & 20 \\
\hline $\begin{array}{c}\text { Point } 2- \\
\text { Low }\end{array}$ & 1,200 & 1.93 & 382 & 20 \\
\hline $\begin{array}{c}\text { Point } 2- \\
\text { High }\end{array}$ & 1,200 & 1.93 & 382 & 20 \\
\hline
\end{tabular}

497 The operability limit in terms of the engine speed was analyzed with a Vibe model as 3D-

498 CFD results were not available. These simulations were performed to test if the chosen

499 turbocharger and coolers could accommodate the engine operation at various engine

500 speeds. The tested engine speed range was from $800 \mathrm{rpm}$ to 2,400 rpm, which represents

501 the idle and top speed for a common heavy-duty engine. The analyzed operating points

502 are specified in Table 8.

503 As can be seen from the compressor performance map, shown in Figure 19, the engine

504 could be operated in this speed range with a few limitations. At $800 \mathrm{rpm}$, the desired level 
505 of SHP pressure could not be obtained while achieving both the desired EGR rates, due to

506 the combination of the low exhaust gas enthalpy and low exhaust gas mass flow at the

507 turbine. As expected, higher intake pressure could be obtained with a $20 \%$ EGR rate due

508 to higher mass flow at the turbine.

509 Table 8. Target conditions for simulated operating points over the engine speed range

\begin{tabular}{|c|c|c|c|c|}
\hline $\begin{array}{c}\text { Operating } \\
\text { Point }\end{array}$ & $\begin{array}{c}\text { Engine Speed } \\
(\mathbf{r p m})\end{array}$ & $\begin{array}{c}\text { Pressure at IVC } \\
(\mathbf{b a r})\end{array}$ & $\begin{array}{c}\text { EGR } \\
(\boldsymbol{\%})\end{array}$ \\
\hline Idle & 800 & 2.01 & 384 & 30 \\
\hline Speed 1 & 1,600 & 2.01 & 384 & 30 \\
\hline Speed 2 & 2,000 & 2.01 & 384 & 30 \\
\hline Top Speed & 2,400 & 2.01 & 384 & 30 \\
\hline Idle & 800 & 2.01 & 384 & 20 \\
\hline Speed 1 & 1,600 & 2.01 & 384 & 20 \\
\hline Speed 2 & 2,000 & 2.01 & 384 & 20 \\
\hline Top Speed & 2,400 & 2.01 & & \\
\hline
\end{tabular}

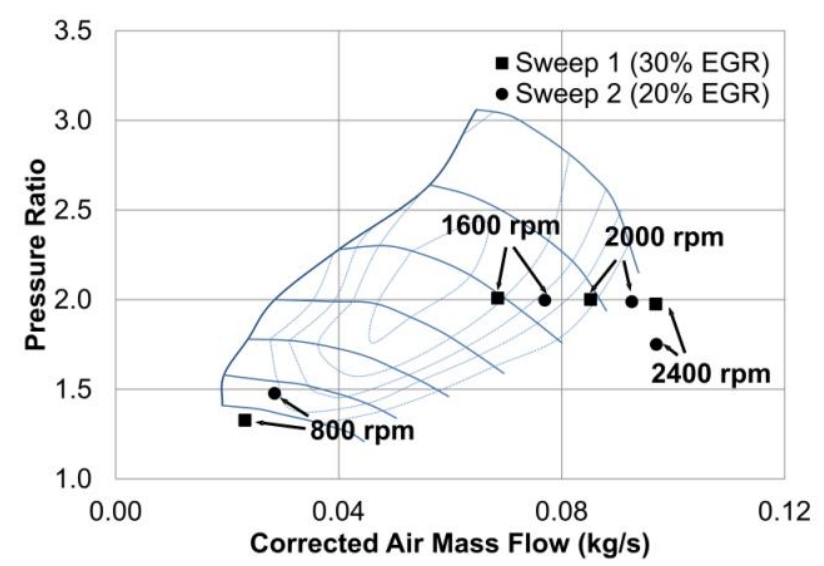

511 Figure 19. Compressor performance map with the referent operating points plotted in it.

512 On the opposite side of the engine speed range, at 2,400 rpm, the compressor was

513 operated in the low efficiency area which led to a considerable deterioration in the engine 
514 breathing (Table 9), which can be seen through the increased exhaust backpressure. As

515 can be seen, at 2,400 rpm the desired IVC pressure could not be obtained with a $20 \%$

516 EGR rate due to significantly deteriorated compressor efficiency.

517 Table 9. The engine performance obtained in the operability range simulation

\begin{tabular}{|c|c|c|c|c|c|c|}
\hline $\begin{array}{c}\text { Operating } \\
\text { Point }\end{array}$ & $\begin{array}{c}\text { Engine } \\
\text { speed } \\
(\mathbf{r p m})\end{array}$ & $\begin{array}{c}\mathbf{p}_{\text {INT }} \\
(\mathbf{b a r})\end{array}$ & $\begin{array}{c}\mathbf{p}_{\text {EXH }} \\
(\mathbf{b a r})\end{array}$ & $\begin{array}{c}\text { EGR } \\
(\boldsymbol{\%})\end{array}$ & $\begin{array}{c}\text { Power } \\
(\mathbf{k w})\end{array}$ & $\begin{array}{c}\text { Torque } \\
(\mathbf{N} * \mathbf{m})\end{array}$ \\
\hline Idle & 800 & 1.32 & 1.61 & 30 & 14.7 & 175.7 \\
\hline Speed 1 & 1600 & 2 & 2.58 & 30 & 50.3 & 300.5 \\
\hline Speed 2 & 2000 & 2 & 2.96 & 30 & 60.9 & 290.7 \\
\hline Top Speed & 2400 & 1.98 & 3.68 & 30 & 61.8 & 245.7 \\
\hline Idle & 800 & 1.48 & 1.85 & 20 & 16.7 & 199.8 \\
\hline Speed 1 & 1600 & 2 & 2.67 & 20 & 49.8 & 296.6 \\
\hline Speed 2 & 2000 & 1.98 & 3.42 & 20 & 56.4 & 271.7 \\
\hline Top Speed & 2400 & 1.75 & 3.45 & 20 & 53.5 & 215.2 \\
\hline
\end{tabular}

\section{4. Conclusions}

519 This study used a RANS 3D-CFD model of an experimental medium duty Homogeneous

520 Charge Compression Ignition engine operating with a Partial Fuel Stratification strategy

521 to optimize a mid-load engine operation point at both the combustion and system levels.

522 It was found that relative to a baseline operating point, the closed-cycle engine operation

523 was improved in terms of indicated efficiency $(0.4 \%), \mathrm{NO}_{\mathrm{x}}$ emissions $\left(0.8 \mathrm{~g} / \mathrm{kw}^{*} \mathrm{hr}\right)$ at

524 the expense of RI $\left(0.7 \mathrm{MW} / \mathrm{m}^{2}\right)$ by carefully tuning intake and direct injection

525 parameters. A second operating point was identified which increased efficiency $(0.2 \%)$

526 and reduced $\mathrm{RI}\left(0.2 \mathrm{MW} / \mathrm{m}^{\wedge} 2\right)$ at the cost of $\mathrm{NO}_{\mathrm{x}}$ emissions $\left(1.7 \mathrm{~g} / \mathrm{kw}^{*} \mathrm{hr}\right)$. In assessing

527 the parametric sweep of operating conditions, it was found that the largest influence on

528 combustion system performance came from the combustion phasing of the engine

529 operating point, with late combustion phasing being required to reduce RI and reduce 
$530 \mathrm{NO}_{\mathrm{x}}$ production. However, excessively late combustion phasing reduced efficiency. The

531 sweep of engine operating points indicated that if $\mathrm{NO}_{\mathrm{x}}$ is to be kept at a low level with

532 efficiency kept high, HCCI-like conditions are most desirable. However, these conditions

533 reduce the ability to control combustion phasing with the direct injection. In the case of

534 higher DI fractions, very late combustion phasing was required to keep $\mathrm{NO}_{\mathrm{x}}$ low, which

535 reduced efficiency.

536 Following the optimization of the in-cylinder engine operating point, a $0 \mathrm{D} / 1 \mathrm{D}$ engine

537 model was created to determine the feasibility and operability limits of the engine, in

538 regards to turbomachinery and thermal regulation. Highlighting the importance of a

539 system level approach, the most efficient point over the high-pressure cycle did not result

540 in the highest overall efficiency of the engine at the system level. This was due to the

541 changes to the turbine inlet conditions caused by the reduced use of EGR and lower

542 intake pressure. By reducing EGR and intake pressure, the mass flow through the turbine

543 increased, while the pressure ratio decreased, which moved the turbine into a lower

544 efficiency range. The peak brake efficiency for the engine, when considering

545 turbomachinery sized for operation of the base case between 800 RPM and 2,400 RPM,

546 was found to be $39 \%$. For this operating condition, intake temperatures in the range of -

$547 \quad 70{ }^{\circ} \mathrm{C}$ to $70{ }^{\circ} \mathrm{C}$ were found to permit the correct IVC conditions through charge and EGR

548 cooling. These results indicate that the engine operating points are viable and competitive

549 with traditional diesel operation, and are more efficient than current spark-ignition

550 operating points at a similar load level. In addition, the move from HCCI to PFS offers

551 the ability to implement additional control over the engine, through altering direct-

552 injection timing or injected fuel mass, as investigated in this paper. These additional 
553 control possibilities make PFS a more realistic combustion system than HCCI, while

554 retaining the high-efficiency, low-emissions operation that is characteristic of lean-burn

555 compression ignition engines.

\section{5. Acknowledgements}

557 This work at the University of California-Berkeley was partially supported by NSF/DOE

558 Award No. CBET-1258653 entitled “Advancing Low Temperature Combustion and Lean

559 Burning Engines for Light- and Heavy-Duty Vehicles with Microwave Assisted Spark

560 Plugs and Fuel Stratification.”

561 This research used resources of the National Energy Research Scientific Computing

562 Center, a DOE Office of Science User Facility supported by the Office of Science of the

563 U.S. Department of Energy under Contract No. DE-AC02-05CH11231.

\section{6. Nomenclature}

565 ACE - advanced combustion engine

566 aTDC - after top dead center

567 BDC - bottom dead center

568 BMEP - brake mean effective pressure

569 bTDC - before top dead center

570 CA50 - crank angle at which $50 \%$ of total heat release has occurred

571 CFD - computational fluid dynamics

$572 \mathrm{CO}$ - carbon monoxide

$573 \mathrm{CR}$ - compression ratio 
574 DI - direct injection

575 EGR - exhaust gas recirculation

576 GDI - gasoline direct injection

$577 \quad \mathrm{H}_{2} \mathrm{O}-$ water

$578 \quad \mathrm{HC}-$ hydrocarbons

579 HCCI - homogeneous charge compression ignition

580 IMEP - indicated mean effective pressure during the closed cycle

$581 \mathrm{IMEP}_{\mathrm{GE}}$ - indicated mean effective pressure during the gas exchange phase

$582 \quad$ IVC - intake valve closure

583 IVO - intake valve opening

584 KHRT - Kelvin-Helmholtz Rayleigh-Taylor

585 LTC - low temperature combustion

$586 \quad \mathrm{~N}_{2}-$ nitrogen

$587 \quad \mathrm{NO}_{\mathrm{x}}-$ oxides of nitrogen

$588 \quad \mathrm{O}_{2}-$ oxygen

589 OP - operating point

$590 \quad \mathrm{p}_{\mathrm{INT}}-$ intake pressure

$591 \mathrm{P}_{\mathrm{EGR}, \text { COOLER }}$ - required cooling power of the EGR cooler

$592 \mathrm{p}_{\mathrm{EXH}}-$ exhaust pressure

593 PFI - port fuel injection

594 PFS - partial fuel stratification

595 PM - fully premixed

596 RANS - Reynolds averaged Navier Stokes 
598 SHP - start of high pressure cycle

599 SMD - Sauter mean diameter

600 TDC - top dead center

$601 \mathrm{~T}_{\mathrm{EXH}}-$ exhaust gas temperature

602 VP - turbine vane position

$603 \eta_{E}-$ brake efficiency

$604 \eta_{\mathrm{T}}$ - turbine efficiency

$605 \eta_{\mathrm{TC}}-$ overall variable geometry turbocharger efficiency

\section{7. References}

607 [1] Saxena S, Bedoya ID. Fundamental phenomena affecting low temperature 608 combustion and HCCI engines, high load limits and strategies for extending these 609 limits. Prog Energy Combust Sci 2013; 39(5): 457-88. $610 \quad$ dx.doi.org/10.1016/j.pecs.2013.05.002.

611 [2] Dec JE, Yang Y, Dernotte J, Ji C. Effects of Gasoline Reactivity and Ethanol 612 Content on Boosted, Premixed and Partially Stratified Low-Temperature Gasoline 613 Combustion (LTGC). SAE Int $\mathrm{J}$ Engines 2015; 8(3): 935-55. 614 dx.doi.org/10.4271/2015-01-0813.

615 [3] Sjöberg M, Dec JE. Smoothing HCCI Heat-Release Rates Using Partial Fuel 616 Stratification with Two-Stage Ignition Fuels. SAE Technical Paper 2006. 617 dx.doi.org/10.4271/2006-01-0629. 
618 [4] Dec JE, Yang Y, Dronniou N. Boosted HCCI - Controlling Pressure-Rise Rates for 619 Performance Improvements using Partial Fuel Stratification with Conventional 620 Gasoline. SAE Int J Engines 2011; 4(1): 1169-89. dx.doi.org/10.4271/2011-01$621 \quad 0897$.

622 [5] Yang Y, Dec JE, Dronniou N, Sjöberg M. Tailoring HCCI heat-release rates with 623 partial fuel stratification: Comparison of two-stage and single-stage-ignition fuels. 624 Proc Combust Inst 2011; 33(2): 3047-55. dx.doi.org/10.1016/jproci.2010.06.114.

625 [6] Yang Y, Dec JE, Dronniou N, Sjöberg M, Cannella W. Partial Fuel Stratification 626 to Control HCCI Heat Release Rates: Fuel Composition and Other Factors 627 Affecting Pre-Ignition Reactions of Two-Stage Ignition Fuels. SAE Int. J. Engines $628 \quad$ 2011; 4 (1): 1903-20. dx.doi.org/10.4271/2011-01-1359.

629 [7] Yang D, Wang Z, J-X Wang JX, Shuai S. Experimental study of fuel stratification 630 for HCCI high load extension, Appl Energy 2011; 88(9): 2949-54. 631 dx.doi.org/10.1016/japenergy.2011.03.004.

632 [8] Wolk B, Chen JY. Computational Study of Partial Fuel Stratification for HCCI 633 Engines Using Gasoline Surrogate Reduced Mechanism. Combust Sci Technol $6342014 ; 186$ (3): 332-54. dx.doi.org/10.1080/00102202.2013.870161.

635 [9] Wolk B, Chen JY, Dec JE. Computational study of the pressure dependence of 636 sequential auto-ignition for partial fuel stratification with gasoline. Proc Combust 637 Inst 2015; 35(3): 2993-3000. dx.doi.org/10.1016/jproci.2014.05.023.

638 [10] Babajimopoulos A, Assanis DN, Flowers DL, Aceves SM, Hessel RP. A fully 639 coupled computational fluid dynamics and multi-zone model with detailed 640 chemical kinetics for the simulation of premixed charge compression ignition 
$\begin{array}{llllll}\text { engines. } & \text { Int } \mathrm{J} & \text { Engine } & \text { Res 2005; 6(5): 497-512. }\end{array}$

642 dx.doi.org/10.1243/146808705X30503.

643 [11] Embouazza M, Haworth D, Darabiha N. Implementation of Detailed Chemical 644 Mechanisms into Multidimensional CFD Using in situ Adaptive Tabulation: 645 Application to HCCI Engines. SAE Technical Paper 2002. 646 dx.doi.org/10.4271/2002-01-2773.

647 [12] Wang Z, Wang J, Shuai S, Zhang F. Numerical Simulation of HCCI Engine With 648 Multi-Stage Gasoline Direct Injection Using 3D-CFD With Detailed Chemistry. 649 SAE Technical Paper 2004. 2004-01-0563. dx.doi.org/10.4271/2004-01-0563.

650 [13] Kong SC, Reitz RD. Application of detailed chemistry and CFD for predicting 651 direct injection HCCI engine combustion and emissions. Proc Combust Inst 2002; 652 29(1): 663-69. dx.doi.org/10.1016/S1540-7489(02)80085-2.

653 [14] Ogink R, Golovitchev V. Gasoline HCCI Modeling: Computer Program 654 Combining Detailed Chemistry and Gas Exchange Processes. SAE Technical 655 Paper 2001. 2001-01-3614. dx.doi.org/10.4271/2001-01-3614.

656 [15] AVL Boost v2013.2 - Theory, AVL LIST GmbH, 2013.

657 [16] Zhou DZ, Yang WM, An H, Li J. Application of CFD-chemical kinetics approach 658 in detecting RCCI engine knocking fuelled with biodiesel/methanol. Appl Energy $659 \quad$ 2015; 145: 255-64. dx.doi.org/10.1016/japenergy.2015.02.058.

660 [17] Li J, Yang WM, An H, Zhao D. Effects of fuel ratio and injection timing on 661 gasoline/biodiesel fueled RCCI engine: A modeling study. Appl Energy 2015; 155: $662 \quad$ 59-67. dx.doi.org/10.1016/japenergy.2015.05.114.

663 [18] Richards KJ, Senecal PK, Pomraning E. CONVERGE 2.1.0. 2013. 
664 [19] Mehl M, Chen JY, Pitz WJ. An approach for formulating surrogates for gasoline 665 with application towards a reduced surrogate mechanism for CFD engine modeling. Energy Fuels 2011; 25(11): 5215-5223. dx.doi.org/10.1021/ef201099y.

667 [20] Wolk BM. Fundamental interactions in gasoline compression ignition engines 668 with fuel stratification (Doctoral dissertation, University of California at Berkeley, 669 published in Berkeley, California, USA).

670 [21] Orszag SA, Yakhot V, Flannery WS, Boysan F, Choudhury D, Maruzewski J, 671 Patel B. Renormalization group modeling and turbulence simulations. Near wall 672 turbulent flows, 1993: 1031-46.

673 [22] Rosin P, Rammler E. The laws governing the fineness of powdered coal. J Inst of $674 \quad$ Fuel 1993; 7: 29-36.

675 [23] Patterson M, Reitz RD. Modeling the effects of fuel spray characteristics on diesel 676 engine combustion and emission. SAE Technical Paper 1998. dx.doi.org/10.4271/980131.

678 [24] Taritas I, Kozarac D, Sjeric M. Numerical Study of Boosting Configurations and 679 Valve Strategies for High Load HCCI Engine in Wide Range of Engine Speed. SAE Technical Paper 2014. dx.doi.org/10.4271/2014-01-1267.

681 [25] Garret Turbochargers, "What is intercooler effectiveness?" 682 www.turbobygarrett.com/turbobygarrett/intercooler-effectiveness, retrieved April 683 2016.

684 [26] Zeldovich YB. The oxidation of nitrogen in combustion and explosions. Acta 685 Physicochim. URSS. 1946; 21(4): 577-628. 
686 [27] Dernotte J, Dec JE, Ji C. Investigation of the Sources of Combustion Noise in HCCI

687 Engines. SAE Int. J. Engines 2014; 7(2): 730-61. dx.doi.org/10.4271/2014-01-

688 1271. 